\title{
Dispositivos de propaganda en el Boletín Titikaka
}

\author{
Mechanisms of propaganda in the "Boletín Titikaka"
}

\author{
César Coca Vargas
}

The Graduate Center - City University of New York, New York, Estados Unidos Universidad Nacional Mayor de San Marcos, Lima, Perú

Contacto: ccoca@gradcenter.cuny.edu

http://orcid.org/0000-0002-9548-1497

\section{Resumen}

A contrapelo de las investigaciones sobre el Boletín Titikaka (19261930), se analizarán los dispositivos propagandísticos ejecutados por su líder, Gamaliel Churata, para entender la naturaleza última del boletín de los "orkopatas". De esta manera, se pretende demostrar que el Boletin Titikaka tuvo como propósito principal la visibilización de un proyecto propio, lo cual significó la utilización interesada del referente andino. Por esta razón, se sostiene que la representación indigenista, a la cual recurrieron constantemente, se encontró subordinada a una agenda que tenía como centro al grupo Orkopata. Se incidirá en la importancia capital que el poemario Ande (1926) cumplió para la concreción de los objetivos de Churata. Puesta la atención en la relación Ande - Boletín Titikaka, se utilizarán dos imágenes de ambivalencia, la "paskana" y la "erisipela", para comprender las nociones de representación, autorrepresentación, participación y agencia.

Palabras clave: Gamaliel Churata; Propaganda; Indigenismo; Boletín Titikaka

\begin{abstract}
In contrast to the research on the Boletin Titikaka (1926-1930), this article will focus on the mechanisms of propaganda executed by its leader, Gamaliel Churata, to understand the ultimate nature of the orkopata magazine. In this way, it is intended to demonstrate that the Boletin Titikaka had as its main purpose the visibility of its own project, which meant the interested utilization of the Andean reference. For this reason, this paper argues that the indigenous representation, which they constantly draw on, was subordinated to an agenda that focused on the Orkopata group. It will influence the capital importance that the poetry book Ande (1926) accomplished for the realization of the objectives of Churata. Paying attention to the Ande - Boletin Titikaka relationship, this research will use two images of ambivalence, "paskana" and "erysipelas", to understand the notions of representation, self-representation, participation and agency.
\end{abstract}

Keywords: Gamaliel Churata; Propaganda; Indigenism; Boletín Titikaka. 
ñawpaqpi amantanipi killa inti ima wiñaypaq tinkirankuku waylluspa

\section{Introducción}

En septiembre de 1927, en el Boletín Editorial Titikaka (BET), Diego Kunurana (Demetrio Peralta) exhibió una xilografía titulada "El ayllu” (imagen 1). En ella, se observa varias casas y algunas mujeres andinas que se encuentran de retorno luego de una jornada laboral. Aparentemente, en dicha imagen no existe resquicio alguno de una presencia de autoridad.

Digo aparentemente pues la xilografía de Kunurana lleva implícita una carga semántica a partir del título que decide otorgarle a su creación. El ayllu, sostienen abundantes investigaciones, fue el núcleo básico de organización en el mundo andino. Fue, asimismo, la unidad elemental de una administración gestionada por el colectivismo que, sin embargo, sí poseía una autoridad. En cuanto a la cosmología andina y la alusión metafórica, esa autoridad recibía el nombre de mallku. En aymara, esta palabra

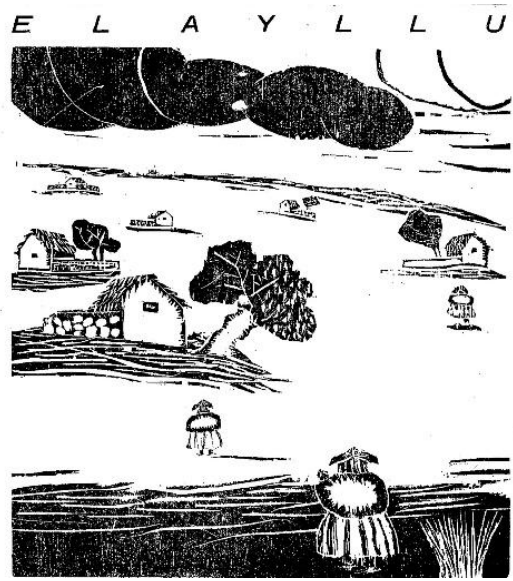

IMAGEN 1 refiere a la parte más alta, al lugar encumbrado, tanto en sentido geográfico como en sentido jerárquico. Así pues, la xilografía de Kunurana, en cuanto alegoría, me permite asegurar que en el grupo Orkopata y su boletín existió una autoridad indiscutible.

La autoridad a la que apunto lleva el nombre de Arturo Peralta (18971969), mejor conocido como "Gamaliel Churata". Churata fue el artífice del proyecto literario-cultural puneño que hoy se conoce con la denominación, a secas, de Boletín Titikaka (BT). Originado a partir de las reuniones del grupo Orkopata (el cual también lideraba Churata), ese proyecto se materializó en una revistaboletín de solo cuatro páginas y de periodicidad mensual, aunque dos veces interrumpida, desde 1926 hasta 1930. 
Estas reflexiones tienen como razón central la naturaleza de la publicación, su génesis y las razones de su nacimiento; además de sus estrategias propagandísticas. Sin embargo, no pretenden abarcar la totalidad temporal del boletín, sino procuran pensarlo a partir del poemario Ande (1926) de Alejandro Peralta (véase Chueca 2006). Con el fin de dar rienda suelta a este propósito, se emplearán dos imágenes de ambivalencia: la "paskana" y la "erisipela". Con la primera, se desea entender la naturaleza de la primera etapa del boletín a partir de las nociones de representación y de autorrepresentación. Mediante la segunda imagen, se busca comprender sus estrategias propagandísticas desde las ideas de participación y de agencia. Gamaliel Churata fue la figura encargada de sostener el proyecto Orkopata; así, a través de ello pensaré en las dos imágenes mencionadas.

\section{Rendijas}

En agosto de 1926, el grupo Orkopata lanzó el primer boletín de su Editorial Titicaca con el apabullante encabezado “"ANDE” Y LA OPINION DE AMERICA [sic]”. Dicho primer número dio a conocer varias notas sobre el poemario Ande de Alejandro Peralta, provenientes de cinco países americanos (Bolivia, Uruguay, Chile, Argentina, además de Perú) y de España (aunque el autor fuera el poeta mexicano Enrique Gonzales). No solo resulta interesante detenerse a analizar el carácter (sus diferencias y sus coincidencias) de dichas notas, sino también observar, con cuidado, la disposición que ellas tienen (sus repliegues y sus despliegues) a lo largo de las páginas del boletín de la Editorial Titicaca. En particular, el número inaugural resulta llamativo tanto por su naturaleza fundacional como por la íntima relación que posee con el poemario Ande. Este libro (compuesto de 22 poemas) vio la luz en abril de aquel mismo año, solo algunos meses antes del lanzamiento de la Editorial Titicaca Boletín (ETB). En tal sentido, la disposición sintáctica y el carácter semántico de las notas de ese primer número desearon estar en sintonía con la nota editorial. A pesar de la importancia semántica del conjunto de notas dedicadas a Ande, no me interesa tanto el detalle pormenorizado de todas esas opiniones (varias decenas). En cambio, tengo el propósito de responder a la pregunta de cuáles fueron las estrategias discursivas que entraron en juego con el objetivo representacional y propagandístico del boletín orkopata. 
En efecto, el número inaugural presentó rasgos sintácticos y semánticos evidentes. En primer lugar, la autodenominación que asumió esta hoja-volante fue "EDITORIAL TITICACA BOLETíN" (imagen 2). Esta construcción gramatical puede ser leída como una oración subordinada, tanto desde su sintaxis como desde su espacialidad. Quiero decir con esto que el hecho de que el encabezado mayor fuera "Editorial Titicaca" definía la naturaleza de esa hoja-volante y, al mismo tiempo, expresaba su voluntad propagandística con el sintagma

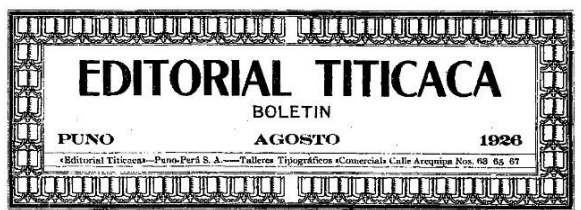

IMAGEN 2 "Boletín". De esta manera, el boletín fue el apéndice dependiente, subordinado, de la Editorial Titicaca; por ende, su existencia como tal estaba supeditada a la empresa editorial liderada por Gamaliel Churata. En términos espaciales, lo que se observa en la portada del referido primer número es una concatenación de los siguientes sintagmas que, por sus características tipográficas, resaltan sobre los otros: “EDITORIAL TITICACA BOLETíN", “ANDE”, “AMÉRICA", "NOTA EDITORIAL” y "FALO" (imagen 3).

Esta concatenación estuvo dispuesta por una verticalidad descendente (con una lectura de arriba hacia abajo) y, en tal sentido, el boletín orkopata no presentó ninguna experimentación espacial de índole vanguardista, al menos en la portada de su primera entrega. Sin embargo, debo reconocer que la utilización de tipografías variadas resultaba sí precursora en el ámbito regional del Perú de inicios del siglo xx. El tamaño de los términos de la referida concatenación, al ser mayor que el de las notas sobre Ande, revelaba no sutil sino expresamente la finalidad comercial de la ETB. Si deseara semantizar toda esta sintaxis espacial, podría afirmar que el objetivo (exclusivo y único, al menos en el número inaugural) del boletín orkopata era comercializar los libros de la editorial que le había dado nacimiento.

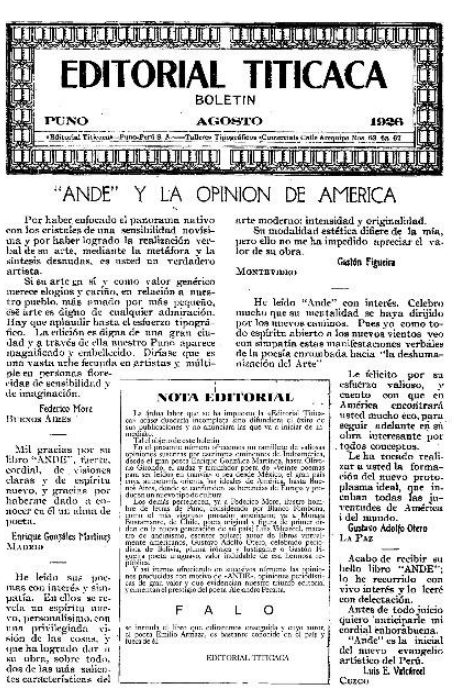


Esta afirmación no es gratuita ni es una revelación inédita mía, sino que se encuentra declarada en su nota editorial: "La ardua labor que se ha impuesto la 'Editorial Titicaca' acaso quedaría incompleta sino [sic] difundiera el éxito de sus publicaciones y no anunciara las que va a iniciar de inmediato" (2016, p. 1).

Dicha nota de la ETB parece ser clara, salvo por un detalle importante: desconocemos en principio su tiraje y no tenemos capacidad de descubrir el “éxito de sus publicaciones", aunque pareciera que algunas investigaciones sí llegan a ese descubrimiento. Resulta sospechoso, por decir lo menos, que - como sostienen Wise (1984, pp. 92-93), Zevallos (2002, p. 46), Monasterios (2015, p. 169), Mamani (2016, p. XII), Usandizaga (2017, p. 31) — el boletín orkopata haya logrado (sos)tener una estrategia de venta y de circulación memorables, hasta el punto de afirmar taxativamente que (ob)tuvo alcance continental. Mucho más cauto, José Tamayo (1982) declara que el impacto que pudo haber tenido el grupo Orkopata en Puno es un aspecto desconcertante de su historia, incluso - y aquí sí lo sigue curiosamente Wise - señala que el grupo y su boletín vivieron en medio de la indiferencia y el silencio entre la población puneña (p. 267). No obstante, al menos en esa primera entrega, se cumplió con el siguiente cometido: el anuncio. La ETB divulgó de inmediata aparición el segundo libro de su Colección Plebeya: "FALO / se intitula el libro que editaremos enseguida y cuyo autor, el poeta Emilio Armaza, es bastante conocido en el país y fuera de él” (2016, p. 1).

Esa misma nota editorial presentó en su cuerpo central dos párrafos dedicados a lo que se hallará en sus páginas sobre Ande. De este modo, la concatenación a la que aludí se encuentra condensada en las palabras de dicho editorial. Así pues, el boletín orkopata nació siendo (o pretendiendo ser) Ande, América, editorial y Falo. En resumen, se está frente al nacimiento de un boletín exclusivamente de propaganda editorial. El juego tipográfico de esta primera página, cuyo aspecto destacó los nombres de las ciudades desde donde se escribieron las notas, permite realizar una conclusión adicional vinculada a los intereses aspiracionales que los orkopatas perseguían. Dicho con otras palabras, su boletín no pretendió formar un diálogo local ni mucho menos dirigir sus preocupaciones al reducido ámbito de Puno. Por el contrario, si bien su lugar de enunciación estuvo marcado por las orillas del lago Titicaca, su anhelo de legitimación y de valoración fue dado por los espacios metropolitanos. En tal sentido, las afirmaciones de Vich 
(2000, p. 78) y de Zevallos (2002, p. 31), respecto de la estrategia orkopata de apropiación y de representación del mundo andino, resultan adecuadas. Lo que propongo (y se discutirá este aspecto en el apartado siguiente) es que el boletín orkopata tuvo un acercamiento ambiguo, muchas veces distante, hacia la población andina.

El grupo de Gamaliel Churata ha sido bautizado por la crítica con varias denominaciones: indigenista (Tamayo, 1982), vanguardista-indigenista (Wise, 1984; Vich, 2000), vanguardista-andino (Espezúa, 2007; Pulido, 2017), vanguardista titikaka (Monasterios, 2015), andinista e indoamericanista (Mamani, 2016). La $E T B$, en su entrega inaugural, empleó las dos últimas denominaciones, las cuales recibieron tratamiento extendido en sus números posteriores. Así, en el tercer párrafo de esa primera nota editorial, la palabra "Indoamérica" salió a flote con el fin de articular no solo geográfica, sino sobre todo culturalmente, al conjunto de opiniones que el boletín orkopata daba a conocer en torno del poemario de Peralta. Con la palabra "Indoamérica", entonces, la Editorial Titicaca pretendió redefinir "América" y particularizarla desde un lugar de enunciación propio (Puno). Por ende, el encabezado programático de dicha primera entrega no sería “ANDE Y LA OPINIÓN DE AMÉRICA”, sino “ANDE Y LA OPINIÓN DE INDOAMÉRICA”. De manera similar, el sintagma "Andinismo" se mostró en esa pequeña nota editorial a través de la figura de Luis Valcárcel, quien en palabras del boletín orkopata era el "maestro del andinismo" por excelencia. La inserción de una figura capital como Valcárcel no fue gratuita (a pesar de las contradicciones que su presencia pudiera haber desencadenado), sino coherente con la estrategia que la ETB perseguía. Como puede observarse, andinismo e indoamericanismo fueron las semillas retóricas, las instancias incoativas, que el grupo Orkopata buscó cosechar a través de su boletín de propaganda editorial.

Entonces, la redefinición que los orkopatas buscaron otorgarle al sintagma "América" fue uno de los mecanismos retóricos más llamativos de su boletín, que tendría su momento de mayor esplendor cuando se denominó BT. Cuando el $B T$ inauguró su última etapa, dos referentes toponímicos acompañaron su encabezado, "INDOAMERIQA" y "TIWANAQU". Ambos, si bien ya presentes en la fase estética e ideológica del boletín orkopata, continuaron reproduciendo el horizonte aspiracional que el grupo de Churata tenía, por medio de (auto)presentarse como 
herederos de una cultura milenaria. De esa manera, contrariamente a Aymará de Llano (2016, p. 76), considero aquí que no se está frente a un posicionamiento ideológico plenamente legítimo, sino ante una apropiación interesada y premeditada del referente quechumara. Todos estos mecanismos retóricos pretendieron alterar la relación monolítica que hasta entonces existía entre centro y periferia culturales, tal como lo ha pensado Mauro Mamani (2016, p. VII), aunque - me parece - de manera hiperbólica. Mamani afirma que el boletín orkopata (él lo llama indiferentemente $B T$ ) fue un claro ejemplo de descentramiento o autocentramiento cultural, debido a que tuvo — sigue Mamani — la capacidad de construir un diálogo internacional desde la periférica ciudad de Puno.

Si se asume la primera parte de la afirmación como cierta, se tendría que sustentarla quizás con la segunda etapa del boletín (desde agosto de 1927, cuando pasa a denominarse BET), no con su momento propagandístico-editorial. Además, si se desea rigurosidad de comprobación, lo asegurado por Mamani en la segunda parte de su razonamiento es sumamente problemático: desde allí se entiende que "el diálogo internacional fue efectivo y plenamente alcanzado". Es decir, que existió un intercambio polifónico internacional articulado desde Puno. Evidentemente, no estoy de acuerdo con esa conclusión, ya que el boletín orkopata nunca fue expresamente un espacio de diálogo, sino más bien un lugar de exposición y difusión de ideas de diversa naturaleza. Mucho menos fue, como también afirma Mauro Mamani, un espacio de encuentro no armónico, porque de haberlo sido no habría podido emplear la palabra "diálogo" sino "polémica" (aunque, llamativamente, Mamani también usa el término).

Con ello no afirmo que el boletín orkopata cuando es ya BET o simplemente $B T$ no haya sido una plataforma de posturas divergentes. Lo que quiero decir en realidad es que, incluso si tomamos la etapa ideológico-estética del boletín, su postura resultó marcadamente ambigua y carente de posicionamiento. Evidentemente esta ambigüedad, con las condiciones estructurales del grupo Orkopata, fue estratégica y para nada problemática respecto de los fines de su boletín. Tanto Juan Zevallos (2004, p. 83) como Dorian Espezúa (2007, p. 232) denominan a esa ambigüedad "posicionamiento intermedio" en relación con el particular indigenismo que los orkopatas practicaron. Por su lado, Cynthia Vich (2000) asegura que la revista fue vocera de un activismo variado (p. 85). Su no-definición, en 
términos pragmáticos, tuvo el propósito de capitalizar el producto de la Editorial Titicaca, esto es, su hoja-volante, mediante diversos dispositivos que intentaré explicar a partir de las imágenes de la paskana y de la erisipela.

\section{La paskana}

En enero de 1929, en la sección "Confesiones de Izquierda" del ya entonces $B T$, Segundo Núñez Valdivia fue consultado sobre su opinión respecto del "estado actual del indio". Hago hincapié, por unos instantes, en el término "indio", ya que esa denominación no parece haber sido tomada ni cándida ni arbitrariamente por el comité editorial orkopata. Dicho término proponía un divorcio entre aquellos otros ("los indios"), a los cuales Churata buscaba representar; y un nosotros (los orkopatas) que se encontraba autorrepresentado en su boletín. Así pues, que la entrevista a Núñez Valdivia haya tenido un apartado dedicado a la "situación del indio" no solo nos revelaría la negación de Churata por lo auténticamente andino, sino también nos mostraría una estrategia de autovalidación simbólica. La respuesta de Núñez a esa inquietud orkopata fue la siguiente: "Vengo a la Sierra después de algún tiempo. Durante el transcurso de algunos años, la transformación del factor humano es sorprendente. En el indio se advierte inmediatamente al hombre. Tiene dos características: inteligencia i [sic] vigor" (Boletín Titikaka, 2016, pp. 106-107).

Estas palabras llaman la atención por dos aspectos. En primer lugar, porque no parece quedar claro quiénes fueron los artífices de aquella transformación del factor humano "indio". En segundo lugar, debido a que tampoco parece estar claro a qué "indios" inteligentes y vigorosos se estuvo refiriendo Núñez. En realidad, poco importa la identificación real de esos individuos, lo que en verdad vale la pena - creo- es identificar los dispositivos de representación que los orkopatas emplearon sobre la cultura andina y los códigos de autorrepresentación que a partir de tales dispositivos pretendieron consolidar. Por esta razón, Núñez Valdivia no habría respondido nada original en realidad, sino solo habría reproducido la (auto) representación que el $B T$ venía llevando a cabo desde su número inaugural. Solo así se puede entender la posición intermedia o ambigua que sus miembros tuvieron: por un lado, representaban interesadamente a la población quechumara; $y$, por otro, se autorrepresentaban como voceros inmediatos de esa misma población. 
El vocablo "paskana" en runasimi (quechua) es un concepto tradicionalmente asociado al mundo rural. Puede significar "lugar o etapa de descanso" y, de manera consecuente, está relacionado con las ideas de travesía, viaje o desplazamiento. Según contaba Emilio Vázquez, cada tarde Gamaliel Churata lideraba sesiones de estudio libre dirigidas a un público de ocupación diversa (maestros, artesanos, pintores, etc.), el cual participaba con el único requisito del compromiso por el estudio. Vázquez agregaba, además, que las reuniones de los sábados podían prolongarse hasta el anochecer y eran conocidas como las "paskanas nocturnas" (Vich, 2000, p. 28). Acerca de estas reuniones se conoce con certeza muy poco, pero parece existir el consenso - en las descripciones que se poseen sobre ellas - de que hubo una suerte de teatralización del intercambio de conocimiento: desde sus protagonistas, casi todos provenientes de sectores emergentes y con inquietudes culturales, hasta los protocolos de socialización que parecen haberse reproducido.

Tamayo Herrera (1982) comenta que en dichas reuniones se bebía chicha y licor, se chacchaba coca, se vestía con chullos, se entonaban canciones en quechua y aymara, se daba lecturas grupales y se impregnaba la habitación con incienso (p. 265). Sea cierta o no esta descripción (y las otras que se conservan), lo destacable es que hubo un grupo de gente interesada en colocar el tema andino en exhibición que, con propósitos puntuales, buscaron asumir la tarea a través de la "representación" andina. Por esta razón, las paskanas fueron espacios singulares de ensayo, mediante los cuales Gamaliel Churata puso en práctica lo que luego materializaría en el boletín orkopata. Su primer ensayo fue la publicación de Ande, primer libro de la Colección Plebeya de su Editorial Titicaca. De modo estratégico, Churata decidió nombrar "plebeya" a la colección que inauguraba y, con esto, ubicar su lugar de enunciación como élite intelectual regional.

Es necesario destacar este último aspecto ya que no considero, como sí lo afirman algunas investigaciones, que el grupo orkopata pretendió democratizar y descentralizar el campo cultural en el Perú. De ningún modo pudo haber sido así, pues ni siquiera en la organización interna de su boletín los orkopatas pudieron consolidar la presencia andina ni apoyaron expresamente las luchas que llevaron a cabo entonces las poblaciones quechuas y aymaras. La pretensión máxima de Churata, aunque ambigua, la identifica sugerentemente Zevallos (2004) al de- 
cir que más bien él tuvo la aspiración de ubicarse en el concierto de la hegemonía cultural peruana (p. 80). Fue esta la razón por la que el boletín orkopata (vocero de Churata) tuvo que colocarse siempre en una posición intermedia entre los sectores campesinos y los intelectuales hegemónicos. Y fue la misma razón por la que la ETB edificó su capital simbólico a partir de opiniones diversas, incluso varias veces contradictorias, sobre el poemario Ande. En mi opinión, las prácticas representativas de las paskanas permitieron que la ETB presentara a Ande como un producto de renovación indigenista, por medio del cual los orkopatas se autorrepresentaban como legítimos herederos de la tradición quechumara. Nada más problemático por la complejidad del referido propósito.

Las paskanas como lugar de ensayo fueron imprescindibles, aunque ellas tuvieran una existencia fugaz y desconocida para la mayoría de la población puneña. Por esta razón, se caracterizaron por haber sido espacios de discusión meramente retórica, en la que afirmaban representar la voz del Ande solo para un radio extremadamente reducido. Sin embargo, esa táctica de suplantación fue contundente en el horizonte internacional, por el hecho de que este ignoraba la problemática social del Perú y no tenía ningún inconveniente en considerar a los orkopatas como legítimos indigenistas. Lo curioso es que también varias revistas culturales peruanas no hayan cuestionado dicha apropiación del referente andino. Sin embargo, la explicación a todo esto es sencilla: tanto los grupos de vanguardia internacional como nacional realizaron diversas apropiaciones de similar calibre a la de los orkopatas. Los que pudieron haber puesto en tela de juicio el arrebatamiento de su problema podrían haber sido las poblaciones andinas que, por aquel entonces, ya tenían mucha conciencia de su situación. En tal sentido, los "mensajeros" fueron los auténticos voceros de las comunidades quechumaras, pues fueron los encargados de llegar a Lima y denunciar las injusticias que sufrían directamente con el gobierno de turno.

La táctica de suplantación se materializó — como afirmé líneas arribacon la aparición de Ande. Fue desplegada, con éxito moderado, a través de las opiniones que la ETB pudo recopilar sobre el poemario. De esta manera, durante sus primeros doce números (primer año de vida del boletín orkopata) el interés estuvo puesto en promocionar Ande, incluso en condicionar la existencia del boletín a la tentativa propagandística de la Editorial Titikaka. Aunque, conforme 
transcurrió el tiempo, los orkopatas terminaron por abandonar el propósito inicial de su editorial. Ese abandono, sin embargo, no impide afirmar que la razón del nacimiento del boletín fue el poemario de Alejandro Peralta. Que, en vista del moderado éxito alcanzado, Churata y los suyos hayan virado la aspiración incoativa, es otra historia. La aludida suplantación debía verse complementada con la capitalización de la $E T B$, la cual por ende debía recurrir a intelectuales de prestigio con el fin de que validaran la representación andina que los orkopatas hacían a través de Ande. Por este motivo, a Churata nunca le interesó lo que se dijese sobre el poemario, le importaba mucho más que la ETB tuviera los nombres de Oliverio Girondo, Ramón Gómez de la Serna, Luis E. Valcárcel, Víctor Raúl Haya de la Torre, José Carlos Mariátegui, José Santos Chocano, etc.

La lista de nombres que la ETB exhibió durante sus primeros doce números respecto del poemario Ande tiene varias singularidades que valdría la pena destacar. En primer lugar, varios de ellos participaron —además de comentar el libro de Peralta - con creaciones propias, sean ensayos o, en su mayoría, poemas: María del Mar, Juan Marín, Magda Portal, Arturo Tronkoso, entre otros más. Este intercambio entre comentadores/creadores y la cúpula orkopata (los hermanos Peralta) nos permite afirmar que detrás de todo eso hubo negociaciones de beneficio mutuo. Las exaltadas palabras de "gran poeta" (Marín), "poeta con lentes de ultravidencia" (Portal), "poema de briosa vitalidad" (Del Mar), no parecen haber sido gratuitas, sino más bien gestos de retribución artística. La revista tuvo respaldo notorio de una red de colaboradores frecuentes que no solo comentaron el poemario, sino que también emplearon el boletín como una plataforma de exhibición propia. En otras palabras, dicho intercambio tiene que ser entendido como una suerte de reciprocidad entre individuos letrados que buscaron afianzarse mutuamente. Por ejemplo, tanto Luis E. Valcárcel como Gamaliel Churata fueron corresponsales de Amauta en sus respectivas regiones.

En segundo lugar, varias de las notas sobre Ande fueron solicitudes expresas de Churata; en otras palabras, fueron respuestas epistolares a un pedido: Oliverio Girondo, Enrique Gonzales Martínez, César Vallejo, Gómez de la Serna, Víctor Raúl Haya de la Torre, entre otros. A los orkopatas no les disgustaba, incluso, que alguno dijera explícitamente que no había leído el libro o que pronto lo haría. Imagino que, por la brevedad de esas notas, sus remitentes no esperaban que 
el acuse de recibo que hacían de Ande fuera publicado en un boletín. A diferencia de los colaboradores nacionales, los extranjeros que alguna vez comentaron sobre Ande no tuvieron apariciones posteriores regulares. Es más, algunos de ellos parece ser que no cumplieron con leer el libro, pues de haberse dado, seguramente la ETB también lo habría anunciado. En sentido estricto, entonces, no se puede hablar de "aportes" que el boletín recibió, sino de solicitudes que la cúpula orkopata realizó. Esta distinción, aunque en apariencia muy pequeña, no la realizan las investigaciones que elogian la "capacidad" de Churata por haber articulado voces de varias latitudes: Mauro Mamani (2016) y César López (2019), por mencionar solo dos. La ETB era el instrumento con el que el grupo buscaba obtener su capital simbólico. Con este propósito, publicitó Ande de todas las maneras posibles, aunque su éxito finalmente haya sido bastante restringido.

En tercer lugar, varios comentarios se referían al libro de modos muy diferentes, y no solo eso, sino que algunos lo calificaban de manera hasta contraria, cosa que no parecía alterar a la ETB. En el boletín, Chocano afirmaba que Peralta era "un gran poeta incaico" $(2016$, p. 6). Mario Nerval decía que era un poeta de "fuerte teogonía incásica" (2016, p. 8). Mariátegui apuntaba de Peralta: “Poeta moderno, 'occidental' de los Andes primitivos, hieráticos y, por ende, un poco orientales" (2016: 10). Alberto Guillén comentaba que el libro era "una bella y brillante colección de imágenes andinistas" (2016, p. 14). Emilio Romero declaraba que Peralta se colocaba en primera línea "dentro de los poetas vanguardistas" (2016, p. 15). Luis Alberto Sánchez consideraba que él era "un poeta de Puno" (2016, p. 15). Ramón Barrenechea concluía: "El poeta vernacular" (2016, p. 35). Así pues, a Churata no le ofendía que llamaran al primer libro de su Colección Plebeya, desde oriental hasta vernacular. Tampoco le incomodaba, por supuesto, que Girondo dijera que apenas había tenido tiempo de hojear el libro (2016, p. 2) o que Haya de la Torre simplemente tomara como excusa la obra para comentar su propia agenda política (2016, p. 21). Mucho menos le fastidió que algunos de sus más admirados promotores culturales solo hayan dedicado contadas líneas de cortesía al poemario: Valcárcel, Mariátegui, Portal, Eguren, Vallejo, etc. Nada de esto interesaba, repito; lo que realmente importaba era que sus nombres le permitieran desplazarse de la periferia cultural a la hegemonía cultural, aunque esta fuera solo pasajera. 
En cuarto lugar, varias opiniones fueron tomadas de otras revistas: la de $\mathrm{Fe}-$ derico Bolaños (septiembre de 1926) de Variedades; la de Mario Nerval (septiembre de 1926) de La República; la de Alberto Guillén (noviembre de 1926) de Amauta; la de Emilio Romero (noviembre de 1926) de Touring Club; la de Carlos Medinaceli (enero de 1927) de Gesta bárbara; la de Julián Petrovich (marzo de 1927) de Hélice, entre otras. Este es un aspecto clave, ya que sí parece comprobar la eficacia de ciertos canjes que alentó el boletín orkopata. Tales opiniones, en efecto, fueron publicadas en otras revistas y, por ende, trazaban un circuito de difusión más abierto del boletín. Sin embargo, de esas solo Gesta bárbara y Hélice eran revistas extranjeras. Entonces, aparentemente no existió reciprocidad verdadera con la gran mayoría de revistas canjeadas, con las cuales decía mantener contacto Churata. Por afinidades más cercanas o por haber sido colaborador antes, el líder de los orkopatas consiguió que Ande fuera reseñado o comentado en otras revistas nacionales. De aquí, pues, que tampoco haya sido gratuita la mención de que la referida nota provenía de tal o cual revista. Esas menciones expresas fueron siempre estratégicas, ya que a la ETB le interesaba dejar en claro el lugar desde donde llegaba determinada nota.

Estas cuatro singularidades que he deseado destacar fueron la puesta en escena de las paskanas, ya que a pesar de las diferencias y matices que reconocemos en cada nota, todas tienen el común denominador de que respaldaron el proyecto de apropiación del mundo andino. Los orkopatas no cuestionaron las contradicciones evidentes en dichas notas, porque lo que les interesaba era ubicarse como voceros inmediatos del Ande y como portadores de una nueva sensibilidad artística. Para este fin, se presentaron y representaron una cosmovisión ajena (la andina) que tuvo una problemática aparición en su boletín. Y aunque mis palabras puedan ser matizadas con la etapa estético-ideológica del boletín orkopata, lo cierto es que durante su fase propagandística la "voz del indio" simplemente estuvo rechazada.

Si se retoma por unos instantes las palabras que Núñez Valdivia dijo respecto del "estado actual del indio", habría que reconocer el éxito de Churata en su propósito de presentarse como el vocero inmediato del Ande. Éxito que, no obstante, solo tuvo cabida en los espacios de la intelectualidad del momento: el grupo Orkopata nunca gozó de legitimidad entre las poblaciones quechuas y aymaras. 
Respecto de este punto, me gustaría comentar el encuentro que sostuvieron José Gabriel Cosío, autor de una extensa nota sobre el poemario de Peralta (Boletín Titikaka, 2016, pp. 17-19), e Inocencio Mamani, autor de algunos poemas quechuas que aparecieron en el boletín. Dicho encuentro o, más bien, entrevista, tuvo lugar en 1928; colocó en escena a dos personas con prestigios y reconocimientos diferentes. Por un lado, Cosío era un catedrático y un destacado indigenista de la Universidad de Cusco. Por otro, Mamani era un quechuahablante que no había seguido estudios superiores. La conversación, alentada por Gamaliel Churata, tenía como propósito exhibir los ensayos de las paskanas a un individuo legitimado como lo era Cosío. Los orkopatas, al llevar a Mamani al encuentro, deseaban que la representación que venían realizando sobre el Ande sea también reconocida por el catedrático cusqueño. Mamani, así, era la carta "más auténticamente india" del grupo.

El pasaje de esa conversación que me interesa destacar tiene que ver con el reclamo que Cosío le hace a Mamani respecto de su genuinidad andina. Por un lado, le increpó que su uso del runasimi no fuera adecuado por haber incorporado modos de expresión castellana y entreverarlos con la lengua quechua. Mamani respondió que él no hacía más que escribir como su comunidad hablaba, pero que reconocía que el runasimi de Cusco era el legítimo heredero del incario. Por otra parte, Cosío lo llamó exótico o, mejor dicho, que era autor de dramas muy exóticos y que debía leer los dramas canónicos para llegar a ser el "genuino cantor de la raza india". Curioso consejo que el profesor cusqueño daba al poeta quechua, pero mucho más curioso que Churata haya expuesto a Mamani con el objetivo de recibir la venia de la autoridad simbólica de Cusco. Para el líder orkopata, ese ensayo era necesario, pues - insisto - necesitaba validar su papel de vocero auténtico. El año de la entrevista, 1928, fue cuando la ETB pasó a ser BT. En otras palabras, se está ya lejos de la fase propagandística y, en principio, en un estadio en que los dispositivos de representación y de autorrepresentación habían sido exitosos en la esfera cultural nacional: el grupo orkopata (se) había (auto)(re)presentado como el fidedigno portavoz de Indoamérica. Sin embargo, las lecciones que Cosío dio a Mamani, exponente de las paskanas, parecen demostrar que no alcanzaron ese prestigio completamente.

Las paskanas fueron el lugar de regocijo de Churata, el espacio donde 
daba rienda suelta a los ensayos que concretaría luego a través de su voz publicitaria y que expondría en ocasiones como las que acabamos de relatar. En tal sentido, no estoy lejos de Zevallos cuando afirma que el boletín estableció un sujeto con propia agenda social y política para configurar una imagen de nación fundada en la representación del indígena (2002, p. 35). Sí, en cambio, me encuentro bastante distantes de Mamani (2016, p. XIII) y de Meritxell Hernando (2010, p. 51) cuando aseguran, respectivamente que la presencia de poetas autóctonos en el boletín fue afirmativa y que el factor lingüístico fue fundamental en su programa. Lo dicho por Mamani puede fácilmente rebatirse si se asegura que la revista, cuando ya era $B T$, apenas publicó contados poemas en lengua andina: de más de ciento cincuenta poemas, solo cuatro (tres de ellos en su última aparición) estuvieron escritos en runasimi. Su presencia fue más bien exótica, característica por cierto que, sin ningún rubor de por medio, menciona sobre el boletín orkopata Wise (1984, pp. 90). Lo concluido por Meritxell Hernando puede ser desestimado si se reconoce que, todo lo contrario, el factor lingüístico en la revista de Churata fue insular y contradictorio: recién en diciembre de 1927 los orkopatas mostraron la propuesta ortográfica de chuqiwanqa [sic], la cual retomaron todavía

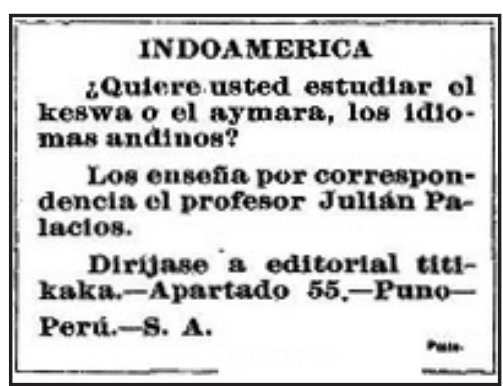
IMAGEN 4 un año después; e hicieron publicidad mínima a las clases de quechua y de aymara que Julián Palacios ofrecía (los espacios que el boletín les dedicó fueron apenas visibles) (imagen 4). Dicho esto, no puede sostenerse con solidez que la lengua haya constituido el fundamento mismo de la revista.

\section{La erisipela}

En el último número del boletín orkopata, Eustakio Aweranka dio a conocer un jarawi dedicado a José Carlos Mariátegui. "José Mariategui Wauqenchis / Wiñaypajj Wiñaypajj Chinkarin [sic]" (imagen 5) fueron las palabras iniciales de esa composición. Considero que esa dedicatoria, la cual podría traducirse como "José Mariátegui nuestro hermano / para siempre, para siempre perdido", juega con las nociones de participación y de agencia que la ETB también desplegó 
durante sus entregas propagandísticas. Leeré el pasaje del mencionado jarawi con el lente de la erisipela para demostrar que los orkopatas, en realidad, tuvieron muy poco margen de maniobra autónoma. Por el contrario, erigieron su prestigio a través del amparo de figuras capitales del indigenismo. La erisipela es una enfermedad infecciosa que afecta a la piel mediante la formación de una

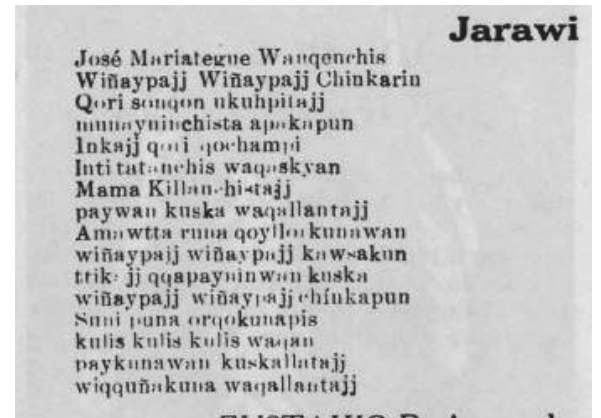
YANA-OKO EUSTAKIO R. Aweranka placa de color rojo, llamativa y dolorosa. Según estudios sobre la enfermedad, casi en un noventa por ciento afecta a las extremidades inferiores del cuerpo. Una persona que padece esa infección es fácilmente reconocible por el vistoso color rojo de la piel.

Precisamente, propongo leer el jarawi de Aweranka bajo la imagen de la erisipela. En él se observa de inicio el nombre de Mariátegui, figura que sirvió de inspiración a los orkopatas, y se destaca un tratamiento de fraternidad y de admiración con el término "wauqenchis". En efecto, Mariátegui fue el promotor cultural más apreciado por Churata, a tal punto de haberle dedicado un número íntegro tras su muerte. Pero no solo fue alguien a quien los miembros del grupo reconocían, sino que fue sobre todo un guía que, sin estar presente físicamente en las paskanas, determinó el cauce de su boletín. En tal sentido, la ETB transitó de su etapa propagandística a su momento estético-ideológico reproduciendo e imitando a Amauta. Por esta razón, sostengo que Churata tuvo poca maniobra autónoma, ya que a cada instante estuvo supeditado a la inspiración de Mariátegui. Tanto en el plano material (habiendo sido corresponsal de ventas de Amauta en Puno), como en el ámbito simbólico (habiendo buscado el reconocimiento de Mariátegui), el líder orkopata estuvo subordinado a la impronta del Amauta.

Las palabras de Aweranka, hay que decirlo, fueron el colofón de un dispositivo que el boletín orkopata utilizó desde su fundación. Me refiero retomando la alegoría de la erisipela — a que la ETB se hizo reconocible a través de su carácter "exótico", al que ella misma apelaba reiteradamente. El color rojo de la 
erisipela era en la revista el singular poemario Ande. De aquí, pues, que su primer año se haya visto impregnado por la "infección" de la propaganda y la búsqueda de la legitimación del capital simbólico de varios promotores culturales. En esta explícita relación de subordinación, Churata y los suyos tuvieron poco impacto en las revistas hegemónicas. Buscaron, en cambio, hacer participar a otros en su $E T B$, con la pretensión de construir un espacio de respetable colaboración. De esta manera debe entenderse las decenas de nombres que se dieron a conocer a partir de la excusa de Ande. En la clausura de su primer tomo (agosto de 1928), Churata declaraba que, habiendo publicado 24 números, en total 96 páginas, en las cuales muy pocas naciones de Indoamérica quedaban sin representación, darían inicio a su etapa titikaka. Precisamente, en las últimas líneas de esa nota, titulada "PRIMER TRAMO DE 'TITIKAKA", se hacía uso de un proverbio aymara (urakheja ssatañataqi hinokatawa [sic]) que era traducido con la afirmación siguiente: "si la tierra existe es para sembrarla" (2016, p. 100).

Las alegorías telúricas y de raigambre "pachamámica" fueron abundantes en el boletín orkopata. El proverbio aymara, así, tiene que ser leído como un eje normativo de los orkopatas. En efecto, la siembra a la que se alude debe ser comprendida por el trabajo emprendido desde la etapa propagandística de la ETB. La contradicción evidente era que el hecho de asumirse como portavoces del Ande, al mismo tiempo, les impedía escapar del dispositivo de la erisipela, esto es, de la exotización de su producción cultural. A pesar de ello, Churata parece haber estado bastante cómodo con el tratamiento que los glosadores realizaron sobre el poemario de su hermano. Es más, la ETB alentaba la exotización mediante el empleo insular de ciertos referentes o idearios andinos. No obstante, es necesario hacer saber que la propuesta orkopata tuvo mucho de elogiable, ya que descubría - por aquellos años - el arte que un grupo intelectual radicado en Puno estaba promoviendo. Si se vuelve a destacar el papel de Churata en la disputa indigenista, es obvio que cumplió una tarea problemática. Un ejemplo notable de esto sería la propuesta "indoamericanista" que los orkopatas publicitaron en todas sus fases.

Desearía referirme, precisamente, al texto de fransisqo chuquiwanka [sic] que el BET publicó en diciembre de 1927 con el título de "ortografia indoamericana [sic]". Allí su autor aludía a la letra "k" que el boletín orkopata 
había asumido desde su segundo número. Chuquiwanka afirmaba: "syendo la $\mathrm{K}$ una letra ejsotiqa en el qastellano los idyomas keshwa o inqa i aymara la an adoptado para rrepresentar un sonido gutural elemental propyo arto frequente en sus palabras [sic]" (2016, p. 65). En mi opinión, la pronta utilización de la "k" por parte de Churata en su boletín fue un ensayo complementario de las paskanas nocturnas. Complementario debido al hecho de que en ningún momento tuvo un despliegue relevante o dedicado como el de la publicidad de Ande. Sin embargo, me interesa destacar la idea que Churata asumió respecto de la propuesta ortográfica de Chuquiwanka, pues tuvo implicancia inmediata en la exotización del boletín. En la propuesta de Chuquiwanka, la "k" (o lo que es la "editorial titikaka [sic]") representaba el sonido gutural propio de las lenguas autóctonas, en ese sentido dichas lenguas se habían apropiado de esa letra. De modo similar, el boletín orkopata se apropió del "referente indígena" y le arrebató al Ande su legitimidad para enunciarse por sí mismo.

El ejercicio fue interesante, pues desplazó a sus agentes más activos mediante la autorrepresentación de una vocería existente solo en los espacios de las paskanas. Churata y la ETB, con sus decenas de notas sobre el poemario de Peralta, desearon capitalizar algunos referentes que habían inscrito en el libro. La Editorial Titicaca había impreso Ande con los siguientes paratextos: "Puno, Perú - Surámerica” (imagen 6) y

1

\author{
E D I T O R I L T I T I C A C A \\ Puno, Perú - Suramérica
}

"ANDE se acabó de imprimir el sábado

24 de abril de 1926 en la Tipografía

\section{IMAGEN 6}

Comercial de don José G. Herrera por los

ANDE

se acabó de

imprimir el sábado 24

de abril de 1926 en la

Tipografía Comercial de don José

G. Herrera por los Hermanos

Camacho-Ávila Ciudad

del Titicaca 3950 metros sobre el Mar

PUNO
Hermanos Camacho-Ávila Ciudad del Titicaca 3950 metros sobre el Mar PUNO [sic]" (imagen 7). Las denominaciones geográficas saltan a la vista y nos permiten reconocer el dispositivo del cual se estaba valiendo la Editorial Titicaca: la singularidad de su propuesta cultural, con sus propios términos, no radicaba en el componente estético-vanguardista, sino en el elemento 
geográfico. Los orkopatas sentían orgullo de anunciarse desde la ciudad de Puno, o lo que era mejor para ellos, desde la ciudad del Titicaca, a la increíble altura de los casi 4000 metros sobre el nivel del mar. No debe sorprender el hecho de que Churata buscara impactar a través de la exotización del lugar desde donde enunciaba, pero sí debe llamar la atención que varias investigaciones repitan la misma retórica (Wise, 1984; Espezúa, 2007; Mamani, 2016; Usandizaga, 2016).

Por esa razón, la aparición de Ande estuvo supeditaba al efecto de lo exótico, marca de la que en ningún momento a Churata le apeteció desprenderse. Desde que la ETB comenzó a publicitar el poemario tuvo que someterse y, por ende, necesitó eliminar su capacidad de agente enunciador del poemario de Peralta. La participación que logró tener en sus primeros doce números terminó por avasallar su propuesta inicial, pues luego de haberse presentado desde las "insondables alturas" fue necesario que asumiera lo exótico como un elogio. Numerosas notas sobre Ande insistieron en la "llamativa cuestión de la geografía": Federico Bolaños (septiembre de 1926), Mario Nerval (septiembre de 1926), Magda Portal (octubre de 1926), César Atahualpa (octubre de 2016), Lucio Díaz (noviembre de 1926), Alberto Guillén (noviembre de 1926), Luis Alberto Sánchez (noviembre de 1926), José María Eguren (diciembre de 1926), José Gabriel Cosío (diciembre de 1926), Carlos Medinaceli (enero de 1927), Lucas Oyague (marzo de 1927), Julián Petrovich (marzo de 1927), Ramón Barrenechea (abril de 1927), Luis Délano (mayo de 1927), Emilio Romero (julio de 1927) y Alberto Ureta (julio de 1927).

De esta manera, existieron alianzas descriptivas que la ETB tomó como propias y que reprodujo sin mediar reflexión de por medio. Lo geográfico, lo novedoso y lo fundacional fueron las etiquetas llamativas que se desplegaron a partir del poemario Ande. La insistencia persistente y reiterativa de sus portadas iniciales fue el dispositivo, en cuanto a estrategia de visibilización, que he denominado "erisipela". La primera entrega de la ETB — como ya se mencionóllevó el encabezado aspiracional de “““ANDE” y LA OPINIÓN DE AMÉRICA”. Sus ediciones inmediatamente posteriores continuaron ese camino: "Alejandro Peralta y su libro 'Ande' [sic]" (septiembre de 1926), "nueva estetica [sic]" (octubre de 1926), "ande [sic]" (noviembre de 1926), "estetica andina [sic]" (diciembre de 1926) y "rutas de "ande" [sic]" (enero de 1927). Solo a partir de su 
séptima aparición, la ETB desplazó el interés que había puesto en el poemario y, de manera complementaria, publicó poesía e imágenes en sus portadas.

Si bien la propaganda del libro de Peralta tuvo importancia manifiesta durante las primeras doce entregas del boletín orkopata, esta fue cuantitativamente diluyéndose: de 7 notas en la primera, segunda y tercera entrega; a 4 en la cuarta; 3 en la quinta y en la sexta; 1 en la séptima; 3 en la octava; 1 en la novena, en la décima y en la undécima, 1 ; y en la duodécima, 2. Aunque las últimas dos notas de la "fiebre" de Ande hayan tenido un comentario al pie que, expresamente, clausuraba la ETB como etapa publicitaria, lo cierto es que, en el cierre de su primer tramo (agosto de 1928), el ya entonces BET retomaría el poemario con las palabras siguientes:

En agosto de 1926 iniciamos la publicación de esta hoja con la finalidad de acendrar el movimiento indígena de la literatura peruana que, a partir de "Ande" de Alejandro Peralta, (abril del mismo año) vieniera [sic] a representar la actividad artística más interesante del Perú, según el juicio ilustre de L. A Sánchez y Jorge Basadre. (2016, p. 100)

Como puede notarse, el relato que los orkopatas iniciaron con la puesta en escena de su primer número volvió a cobrar sentido enunciativo en su entrega número veinticuatro. Aunque este haya sido un gesto de nostalgia propagandística (el boletín nunca promocionó de manera similar otro libro que no haya sido Ande), era necesario que, a efectos de las demandas de participación y de agencia, pudiera construir una narrativa acerca de la vocería que decía haber asumido desde agosto de 1926. La posición intermedia que el grupo Orkopata afianzó se encontró subordinada a las figuras capitales que exhibía en las páginas de su boletín. Por esta razón, publicaron notas tan divergentes respecto del libro de Peralta, a tal instancia que jamás llegaron a cuestionar absolutamente nada de lo que de él se decía. La reciprocidad, por supuesto, también estuvo dada en que casi la totalidad de esos comentarios fue sumamente condescendiente en sus juicios sobre Ande. Una excepción (aunque solo de detalle) fueron las siguientes palabras de Armando Bazán en su nota de enero de 1927: “A veces por la persistencia de imágenes anteriores sus poemas se resienten de la maestría con que fueron principiados" (2016, p. 24). 
En julio de 1927, un mes antes de que la ETB pasara a ser BET, los orkopatas aseguraron que la nota de Emilio Romero cerraba la serie numerosa de opiniones que, respecto de Ande se había publicado (2016, p. 48). El dispositivo de la erisipela, entonces, había permitido visibilizar el boletín orkopata a través de la propaganda del poemario. Pero a su vez, había silenciado, o en el mejor de los casos, había moldeado la aspiración andinista del grupo. La indefinición en que se encontró Churata durante los primeros doce números de su revista es clamorosa, ya que - como se ha explicado - permitió que el primer libro de su editorial recibiera cualquier calificativo. Palabras como: "Yo sé decirle que fué [sic] uno de los primeros libros que he recibido de Perú" (María del Mar respecto de la invitación de Churata); o: "He recibido su magnífico libro de versos Ande [sic]. Le envío un abrazo de felicitación calurosa" (Haya de la Torre sobre una invitación similar del líder orkopata), fueron consecuencia inmediata de las solicitudes que, en buena cuenta la dirección del boletín había iniciado luego de la aparición de Ande. En estos términos debe entenderse la idea de participación en la $E T B$, pero incluso más allá: la apropiación y el requerimiento fueron los ensayos predilectos del modo de trabajo orkopata.

Churata como agente es otra idea interesante de comentar. Como portavoz autonombrado, él lideró un grupo y una revista que fueron medianamente conocidos en algunos circuitos culturales del Perú: Lima, Cusco y Arequipa, principalmente. La evidencia de esta afirmación está en el hecho de que el propio Churata escribió en algunas revistas nacionales, antes o durante el tiempo de existencia del boletín orkopata. Afirmamos con esto que seguramente la distribución de la ETB, el BET y el $B T$ fue alcanzada en los espacios en que el líder orkopata estuvo presente en algún momento. Sin embargo, la capacidad de agenciar un ideario propio parece ser que estuvo subordinada a sus relaciones con figuras fundamentales y que él mismo consideraba necesarias. Luis E. Valcárcel, Federico More, José Carlos Mariátegui y Víctor Raúl Haya de la Torre son ejemplos notables de ello. Hay que mencionar que, en abril de 1927, la ETB publicó un breve texto de Federico More sobre el andinismo.

Hay que recordar, además, que Gamaliel Churata fue corresponsal de ventas de Amauta en Puno (imagen 8), oficio que cumplió con mucha dedicación. 
$\mathrm{Y}$ es necesario también indicar que la noción de "indoamericanismo" fue un aporte de Haya de la Torre, quien bautizó el concepto en términos que luego empleó el grupo Orkopata. Como puede notarse, la elaboración del pensamiento indigenista que sostuvo a Churata fue, en realidad, una apropiación de ideas anteriores

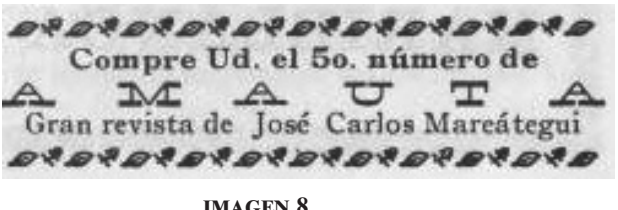
IMAGEN 8 a él. En tal sentido, lo que Churata pretendió hacer no fue transformar o superar esas nociones, sino solo tomarlas con el propósito de publicitarlas. El boletín orkopata, fundado a partir de la justificación de Ande, llevó a cabo dicho propósito desplegando todas las posibilidades que una ciudad como Puno le podía brindar. El mérito más notable de Churata, por ende, radicó en el uso estratégico de los dispositivos que empleó para hacer conocido —al menos en el corto horizonte cultural de aquel entonces - su grupo, su boletín y hacerse conocido él mismo.

\section{Notas}

1 Seguiré las distintas denominaciones que tiene la hoja-volante del grupo Orkopata: 1) de agosto de 1926 a julio de 1927, "Editorial Titikaka Boletín" (con excepción del primer número, en el que se escribe "Titicaca"); 2) de agosto de 1927 a agosto de 1928, "Boletín Editorial Titikaka"; y 3) desde diciembre de 1928 hasta su último número, simplemente "Boletín Titikaka".

2 La cuestión del liderazgo de Gamaliel Churata parece ser de pleno consenso. Tanto Inocencio Mamami como Emilio Vázquez, miembros del grupo Orkopata, lo reconocieron en reiteradas oportunidades (Tamayo, 1982, pp. 258-259; Vich, 2000, p. 28; Zevallos, 2002, p. 25). De importancia notoria es la sección "Valoración" del libro Antología y valoración, de Gamaliel Churata, publicado en 1971. Allí se reúnen numerosos testimonios de personas que tuvieron alguna relación, ciertas veces muy cercana, con Churata.

3 Son escasas las oportunidades en las que el boletín (en cualquiera de sus etapas) mostró explícitamente un editorial o una nota editorial. Sus primeras entregas fueron excepciones; o aquellas en las que cerraba, de manera expresa, una etapa.

4 Con el fin de no agobiar a los lectores, emplearé la denominación "boletín orkopata" para referirnos al conjunto de los boletines titikaka.

5 De ahora en adelante, todas las referencias del boletín orkopata se tomarán de la coedición que realizaron el Centro de Estudios Literarios Antonio Cornejo Polar y Lluvia Editores en el año 2016. 
6 No soy el primero que sostiene este rasgo del boletín orkopata (Wise, 1984; Vich, 2000; Zevallos, 2002). Desde su nacimiento, la publicidad y la propaganda determinaron cada uno de sus números, aunque a la larga termine privilegiando la cuestión estética e ideológica, sobre todo en su fase de Boletín Titikaka. Prescindimos del artículo de Luis Veres (2006-2007) por su falta de rigor académico.

7 En abril de 1927, la ETB (cuando ya empleaba la grafía "k" para “Titikaka") presentó el ensayo titulado "El andinismo" de Federico More (Boletín Titikaka, 2016, p. 39). En noviembre de 1927, su portada fue bautizada con el nombre de "Indoamericanismo" (Boletín Titikaka, 2016, p. 67).

8 Me parece atractivo el argumento de Elizabeth Monasterios (2015) sobre el surgimiento del término "andinismo", cuyo razonamiento también se puede extrapolar a la idea de Indoamérica. Monasterios sostiene que esa categoría, antes de ser étnica o cultural, fue una estrategia geopolítica de promoción (p. 165).

9 Valcárcel abogaba en varias de sus conferencias y, en particular, en Tempestad en los Andes (1927) por la concreción mesiánica de la ucronía andina. De aquí la contradicción que su presencia pudo generar entre los orkopatas, quienes más bien defendían las diferentes variantes del mestizaje; es decir, una propuesta mucho más cercana a la de Uriel García.

10 Utilizo el término en el sentido que Terrence Kaufman (1990) valida. Aunque él emplee "quechumara" para afirmar la existencia de una macrofamilia de lenguas indoamericanas a partir del quechua y del aymara, nos parece que podemos emplear el concepto también en términos culturales y de cosmovisión.

11 Cynthia Vich (2000) menciona la apertura que el boletín orkopata tuvo frente a posturas tan divergentes como el conservadurismo ideológico de Valcárcel y la actitud transculturadora del mestizo Uriel García; o marcadamente enfrentadas como el socialismo indigenista de Mariátegui y el indoamericanismo singular de Haya de la Torre (pp. 92-101).

12 Juan Zevallos (2002) sostiene que el núcleo central del grupo estuvo conformado por Gamaliel Churata, Alejandro Peralta, Inocencio Mamani, Emilio Vázquez, Diego Kunurana, Mateo Jaika y Eustaquio Aweranka (p. 24).

13 Resultaría interesante estudiar con detalle la participación de los "mensajeros" durante el gobierno de Augusto B. Leguía, el cual alentó inicialmente la reivindicación "indígena" e incluso fue conocido con el nombre de "Wiracocha".

14 Esta afirmación no solo puede referirse a las notas sobre Ande que la ETB mostró, sino que también fue una práctica para llenar de contenido los números. Churata y los suyos leían algunas revistas hispanoamericanas, principalmente, argentinas al parecer, y tomaban ciertos textos para publicarlos en su boletín. El caso de Jorge Luis Borges es emblemático en ese sentido.

15 Varias notas se refieren a Ande como un poemario dadaísta, surrealista, ultraísta, andinista, etc. 
16 En una carta, que data del 11 de enero de 1929, Churata se dirigió a Mariátegui con el fin de "reclamarle" el no haber incluido al poemario Ande en su ensayo dedicado a la literatura peruana: "Algo que me ha llamado fuertemente la atención, es la prescindencia que hace de Alejandro al ajustar un momento de nuestra literatura. Veo que alcanza usted a Mamani y olvida por modo sorprendente el papel histórico de Ande en nuestras letras, y en nuestras letras cuando vienen a representar un síntoma político. Juzgo, en todo caso, que usted ha omitido involuntariamente la crítica de 'Ande' [sic] y de su tendencia, ya suficientemente generalizada y valorizada para que sea posible olvidarla" (véase en el archivo digital de Mariátegui).

17 Vida Femenina (Montevideo), Cultura Venezolana (Caracas), Ulises (Ciudad de México), Panorama (Santiago), Revista de avance (La Habana), Martín Fierro (Buenos Aires), entre varias otras.

18 Hay que decir que Gerardo Leibner (2003) recrea con detalle la entrevista que Cosío le realizó a Mamani en 1928.

19 Sin embargo, he evitado emplear el término "indígena" en nuestras reflexiones, pues nos parece que posee una carga colonialista notoria, pero que además no tiene correlato ya con el siglo XX, tiempo en que las poblaciones andinas no podían ser comprendidas solo "racialmente".

20 More ya había publicado sus ideas sobre el punto en su libro Deberes del Perú, Chile y Bolivia en 1918.

21 Desde Puno, el 11 de enero de 1929, Churata le escribía una carta en los siguientes términos: "Desgraciadamente estoy en deuda con usted. $\mathrm{Y}$ ahora creo que se concluye mi paciencia. Los agentes de provincia toman a broma mis circulares, y me obligan esta vez más a cancelar yo sus deudas como ya la vez pasada ocurrió" (véase el archivo digital de Mariátegui).

22 El 7 de mayo de 1924, Haya de la Torre, en calidad de presidente de la Federación de Estudiantes del Perú, pronunció un discurso destinado a la "América vasta", en la Ciudad de México (Torres, 2004, p. 217).

\section{Referencias bibliográficas}

Boletín Titikaka [1926-1930]. (2016). Edición facsímile. Lima: Centro de Estudios Literarios Antonio Cornejo Polar, Lluvia Editores.

Chueca, L. F. (2006). Alejandro Peralta y la vanguardia indigenista de los años veinte. Introducción a Ande/Kollao [1926/1934] (pp. 7-22). Lima: Pontificia Universidad Católica del Perú.

Churata, G. (1971). Antología y valoración. Lima: Editorial Instituto Puneño de Cultura. 
De Llano, A. (2016). Tinkuy en el Boletín Titikaka. Zama, 3 (8), 15-83.

Espezúa Salmón, B. (2007). Vanguardismo andino en el Boletín Titikaka. CELEHIS - Revista del Centro de Letras Hispanoamericanas, 16 (18), 219-245.

Hernando Marsal, M. (2010) Una propuesta lingüística vanguardista para América Latina. Estudio, 18 (35), 49-75.

Kaufman, T. (1990). Language History in South America: What we know and how to know more. En D. L. Payne. Amazonian Linguistics (pp. 13-74). Austin: University of Texas Press.

Leibner, G. (2003). Indigenismo, autoridad intelectual y jerarquías sociales: dos reportajes a un indio en Amauta. Histórica, 27 (2), 467-483.

López Núñez, C. (2019). Tres cuestiones sobre el Boletín Titikaka. El Hablador, 23. Recuperado de: https://www.elhablador.com/articulos23_lopez. html.

Mamani Macedo, M. (2016). El Boletín Titikaka: tinkuy e irradiación cultural. Introducción a la edición facsímile de Boletín Titikaka [1926-1930] (pp. VII-XVII). Lima: Centro de Estudios Literarios Antonio Cornejo Polar, Lluvia Editores.

Monasterios Pérez, E. (2015). La vanguardia plebeya del Titikaka. Gamaliel Churata y otras beligerancias estéticas en los Andes. Puno: Universidad Nacional del Altiplano.

Pulido Herráez, B. (2017). El Boletín Titikaka y la vanguardia andina. Ciudad de México: Universidad Nacional Autónoma de México, CIALC.

Tamayo Herrera, J. (1982). Historia social e indigenismo en el altiplano. Lima: Ediciones Treintaitrés.

Torres, L. A. (2004). La semántica política de Indoamérica 1918-1941. En A. Granados y C. Marichal (Eds.), Construcción de las identidades latinoamericanas (pp. 207-240). Ciudad de México: Colegio de México.

Usandizaga, H. (2016). Presentación. Edición facsímil de Boletín Titikaka [19261930] (pp. XIX-XXIII). Lima: Centro de Estudios Literarios Antonio Cornejo Polar, Lluvia Editores. 
Usandizaga, H. (2017). El Boletín Titikaka en los años 20: cambiando el mapa del saber. Entre canibales, 1 (7), 31-38.

Valcárcel, L. E. (1927). Tempestad en los Andes. Lima: Populibros Peruanos.

Veres Cortés, L. (2006-2007). Periodismo político y cultural en la década de 1920: el Boletín Titikaka y la propaganda. Espéculo, 34. Recuperado de: https://webs.ucm.es/info/especulo/numero34/titikaka.html.

Vich, C. (2000). Indigenismo de vanguardia en el Perú: un estudio sobre el Boletín Titikaka. Lima: Fondo Editorial de la Pontifícia Universidad Católica del Perú.

Wise, D. (1984). Vanguardismo a 3800 metros: el caso del Boletín Titikaka (Puno, 1926-1930). Revista de Crítica Literaria Latinoamericana, 10 (20), 89100.

Zevallos Aguilar, J. (2002). Indigenismo y nación. Los retos a la representación de la subalternidad aymara y quechua en el Boletín Titikaka (19261930). Lima: Instituto Francés de Estudios Andinos, Fondo Editorial del Banco Central de Reserva del Perú. https://doi.org/10.4000/books. ifea.449

Zevallos Aguilar, J. (2004). Vanguardismo literario andino y modernidades alternativas en el Sur peruano (1900-1930). Boletín Hispánico Helvético, 4, 79-91. 